\title{
The effect of myometrial invasion and histological grade on lymph node metastasis in patient with early stage endometrium cancer
}

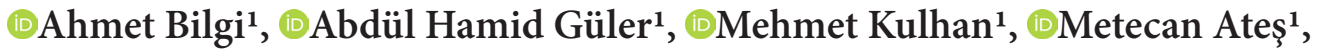 \\ (1)Havva Hande Keser Şahin ${ }^{2}$, ®Çetin Çelik ${ }^{1}$ \\ ${ }^{1}$ Selçuk University Faculty of Medicine, Department of Gynaecology and Obstetrics, Konya, Turkey \\ ${ }^{2}$ Hitit University Faculty of Medicine, Department of Pathology, Çorum, Turkey
}

Cite this article as: Bilgi A, Güler AH, Kulhan M, Ateş M, Keser Şahin HH, Çelik Ç. The effect of myometrial invasion and histological grade on lymph node metastasis in patient with early stage endometrium cancer. J Health Sci Med 2021; 4(5): 552-556.

\begin{abstract}
Aim: Early detection of endometrial cancer is important for the prognosis of the disease. In our study, the effect of myometrial invasion and histological grade on lymph node metastasis was investigated in patient with early stage endometrium cancer .

Material and Method: A total of 249 patients from the last 10 years who underwent systemic lymphadenectomy for staging in our hospital were retrospectively examined. The pathologies of these patients were limited to the uterine corpus. The effect of histological grade of tumor and myometrial invasion on lymph node metastasis was evaluated statistically.

Results: The average lymph node collected from patients was 27.7 (11-78). Lymph node metastasis was detected in $4.1 \%$ of patients with histological grade $1-2$ and $<1 / 2$ myometrial invasion. Lymph node metastasis was detected in $18.3 \%$ of patients with grade 1-2 tumors with myometrial invasion $\geq 1 / 2$. Lymph node metastasis was detected in $11.1 \%$ of patients with myometrial invasion $<1 / 2$ and histological grade 3 . Lymph node metastasis was detected in $27.3 \%$ of patients with myometrial invasion $\geq 1 / 2$ and histological grade 3 .

Conclusions: The most important findings of our study are that histological degree and myometrial invasion are common independent markers for retroperitoneal lymph node metastasis in early stage endometrium cancers and demonstrate the necessity of lymphadenectomy.
\end{abstract}

Keywords: Endometrium cancer, lymph node metastasis, staging, myometrial invasion

\section{INTRODUCTION}

Unlike most other cancers, the incidence of endometrial cancer (EC) and death rates associated with it are increasing (1). EC is the sixth most common cancer in women and the 14th leading cause of cancer deaths worldwide (2). Hysterectomy and bilateral salpingo-oophorectomy combined with extensive lymph node dissection are standard for staging most ECs (3). One of the most important prognostic factors in EC is the presence of extrauterine disease including pelvic and paraaortic lymph node metastases (LNM). Lymphadenectomy during hysterectomy can provide a therapeutic benefit by providing an accurate assessment of the extent of the disease (4). In addition, lymphadenectomy has been proven to increase the surgical time and increase the risk of surgery-related morbidity, lymphocyst and lymphedema formation
(5). Approach to lymph node evaluation especially in patients with early stage EC is controversial $(6,7)$. Many gynecological oncologists agree that women with "low risk" EC do not require routine lymphadenectomy, but the definition of "low risk" is still difficult (8). Two randomized studies have shown that routine lymphadenectomy does not affect survival in patients with low-risk EC $(9,10)$. Despite these facts, routine lymph node dissection is strongly recommended by some experts in all women with EC, regardless of the presence or absence of suspected lymph nodes (11). In a survey of GOG (Gynecological Oncology Group) members, it was found that up to $35 \%$ of experts performed both pelvic and paraaortic lymphadenectomy for grade I EC (12). Various models have been proposed to estimate the likelihood of lymph 
node metastasis using histopathological parameters in women with EC. One of these models was described in a study conducted at the Mayo Clinic. Comprehensive lymphadenectomy was performed on 187 patients with low-risk EC as part of their surgical staging in that study. Only 9 (5\%) of 187 people had LNM, if the tumor size was less than $2 \mathrm{~cm}$, no patient with LNM was detected in the low-risk group (13). Many retrospective analyzes have shown similar results in patients with low-risk characteristics $(6,14)$.

The aim of this study is to evaluate the risk of nodal metastasis in patients with EC, whose disease is apparently confined to the uterine corpus, using data from our tenyear EC experience.

\section{MATERIAL AND METHOD}

This study was approved by Selçuk University Local Ethics Committee (Date: 05.05.2021, Decision No: 2021/247). All procedures were carried out in accordance with the ethical rules and the principles of the Declaration of Helsinki.

A total of 412 cases of EC who underwent surgical treatment between 2010 and 2019 in the Department of Obstetrics and Gynecology, Faculty of Medicine, Our University, were detected. The study population was formed with 249 patients whose disease was limited to the uterine corpus. According to the 2009 International Federation of Gynaecology and Obstetrics (FiGO) staging, the entire study group was in stage I. Endometrioid histological type, histological grade I-IIIII, patients with EC who had undergone both pelvic and paraaortic lymphadenectomy and whose disease was apparently confined to the uterine corpus were considered as inclusion criterias. Non-endometrioid or mixed histology, disease involving the cervix, adnexa, or peritoneal cavity, and only pelvic lymphadenectomy or only paraaortic lymphadenectomy were determined as exclusion criterias. Patients without data on tumor invasion, size and histological grade were excluded. Clinico-pathological data of the patients were obtained from the computerized database of our hospital and performed in a retrospective study format. A flow chart of the study design is presented in Figure 1. All procedures were done by gynecologist oncologists. Total abdominal hysterectomy, bilateral salpingooophorectomy, cytological sampling, pelvic and paraaortic lymphadenectomy were performed in all patients. The patients were divided into two groups according to lymph node involvement. The first group consisted of those with positive lymph nodes, and the second group consisted of those with negative lymph nodes. Then each group was divided into 4 subgroups within itself. The subgroups were defined as follows.
1. low grade (grade1-2) and less than $1 / 2$ myometrial invasion; 2. low grade (grade1-2) and more than $1 / 2$ myometrial invasion; 3 . those with high grade (grade 3 ) and less than $1 / 2$ myometrial invasion; 4 . those with high grade (grade 3 ) and more than $1 / 2$ myometrial invasion. In this study; Parameters determining high and low risk in endometrioid type cancers were analyzed separately. Clinical and pathological characteristics of the patients, age, histological subtype, grade, depth of myometrial invasion and presence of LNMs were evaluated.

\section{Statistical Analysis}

Statistical evaluation was performed using the SPSS 20 (Statistical Package for Social Sciences) for Windows (IBM SPSS Inc., Chicago, IL) program. The normal distribution of the data was evaluated with the Kolmogorov-Smirnov test. Among the numerical variables, those with normal distribution were shown as mean \pm standard deviation, and those without normal distribution were shown as the median (min-max). Categorical variables were expressed as numbers and percentages.

\section{RESULTS}

A total of 249 patients who were operated with a diagnosis of EC in our hospital and whose disease was found limited to the uterine corpus according to the final pathology result were included in the study. The median age of the cases was found to be 59 (33-88 years). Tumor type was endometrioid type in 249 patients (100\%). The median number of pregnancies was $3(0-8)$. Although 12 patients $(4.8 \%)$ never gave birth, 28 patients $(11.2 \%)$ had 5 or more pregnancies. The first presentation symptom was vaginal bleeding in 229 patients (91.9\%). While there was no myometrial invasion (MI) in 185 of the patients (74.3\%), it was found that the tumor had spread up to the serosa in $64(25.7 \%)$ of them. The rates of grade I, II, III patients were 168 (67.5\%), 61 (24.5\%), 20 (8\%), respectively. The main characteristics of patients with endometrioid EC whose disease were apparently limited to the uterine corpus, are summarized in Table 1. The median lymph nodes number was 33.0 and ranged from 4 to 91 . This number was 15.7 (range: 1-55) for the paraaortic area and 26 (range: 4-71) for the pelvic area. LNM was observed in $22(8.8 \%)$ patients. Pelvic and pelvic+paraaortic LNM rates were $4 \%$ and $3.6 \%$, respectively. The isolated paraaortic LNM rate was $1.2 \%$. When factors affecting LNMs are evaluated, LNM was detected in $4.1 \%$ of patients with grade 1-2 tumors and $<1 / 2$ MI. LNM was detected in $18.3 \%$ of patients with grade 1-2 tumors with $\mathrm{MI} \geq 1 / 2$. LNM was detected in $11.1 \%$ of patients with grade 3 tumors with MI below $50 \%$, and in $27.3 \%$ of patients with MI above $50 \%$. LNM patterns of the patients are summarized in Table 2. 


\begin{tabular}{|c|c|c|}
\hline Mean Age $\pm S D$ (Range) & $59.38 \pm 10.44$ & $(33-88)$ \\
\hline Median Gravida $\pm S D$ (Range) & $3.0 \pm 2.14$ & $(0-8)$ \\
\hline $\begin{array}{l}\text { Median Lymph Node } \\
\text { Number } \pm S D \text { (Range) }\end{array}$ & $33.0 \pm 16.86$ & $(4-91)$ \\
\hline $\begin{array}{l}\text { Median Pelvic Lymph Node } \\
\text { Number } \pm \text { SD (Range) }\end{array}$ & $26.0 \pm 12.44$ & $(4-71)$ \\
\hline $\begin{array}{l}\text { Median Paraaortic Lymph } \\
\text { Node Number } \pm S D \text { (Range) }\end{array}$ & $15.7 \pm 23.12$ & $(1-55)$ \\
\hline Grade & n & $\%$ \\
\hline 1 & 168 & 67.5 \\
\hline 2 & 61 & 24.5 \\
\hline 3 & 20 & 8.0 \\
\hline Myometrial Invasion (MI) & n & $\%$ \\
\hline$<1 / 2 \mathrm{MI}$ & 185 & 74.3 \\
\hline$\geq 1 / 2 \mathrm{MI}$ & 64 & 25.7 \\
\hline
\end{tabular}

Table 2: Lymph node metastasis patterns of patients with

endometrioid endometrial cancers whose disease were apparently limited to uterin corpus

\begin{tabular}{|c|c|c|}
\hline & $\mathbf{n}$ & $\%$ \\
\hline \multicolumn{3}{|l|}{ Lymph node metastasis } \\
\hline No & 227 & 91.2 \\
\hline Yes & 22 & 8.8 \\
\hline \multicolumn{3}{|l|}{ Pattern of lymph node metastasis } \\
\hline Only Pelvic LNM & 10 & 4.0 \\
\hline Only Paraaortic LNM & 3 & 1.2 \\
\hline Both Pelvic and Paraaortic LNM & 9 & 3.6 \\
\hline \multicolumn{3}{|c|}{$\begin{array}{l}\text { Lymph node metastasis among patients } \\
\text { with grade } 1-2 \text { tumor and }<1 / 2 \mathrm{MI}\end{array}$} \\
\hline No & 162 & 95.9 \\
\hline Yes & 7 & 4.1 \\
\hline \multicolumn{3}{|c|}{$\begin{array}{l}\text { Lymph node metastasis pattern among } \\
\text { patients with grade } 1-2 \text { tumor and }<1 / 2 \mathrm{MI}\end{array}$} \\
\hline Only Pelvic LNM & 2 & 1.2 \\
\hline Only Paraaortic LNM & 3 & 1.8 \\
\hline Both Pelvic and Paraaortic LNM & 2 & 1.2 \\
\hline \multicolumn{3}{|c|}{$\begin{array}{l}\text { Lymph node metastasis among patients } \\
\text { with grade } 1-2 \text { tumor and } \geq 1 / 2 \mathrm{MI}\end{array}$} \\
\hline No & 49 & 81.7 \\
\hline Yes & 11 & 18.3 \\
\hline \multicolumn{3}{|c|}{$\begin{array}{l}\text { Lymph node metastasis pattern among } \\
\text { patients with grade } 1-2 \text { tumor and } \geq 1 / 2 \mathrm{MI}\end{array}$} \\
\hline Only Pelvic LNM & 5 & 8.3 \\
\hline Only Paraaortic LNM & 0 & 0 \\
\hline Both Pelvic and Paraaortic LNM & 6 & 10.0 \\
\hline \multicolumn{3}{|c|}{$\begin{array}{l}\text { Lymph node metastasis among patients } \\
\text { with grade } 3 \text { tumor and }<1 / 2 \text { MI }\end{array}$} \\
\hline No & 8 & 88.9 \\
\hline Yes & 1 & 11.1 \\
\hline \multicolumn{3}{|c|}{$\begin{array}{l}\text { Lymph node metastasis pattern among } \\
\text { patients with grade } 3 \text { tumor and }<1 / 2 \mathrm{MI}\end{array}$} \\
\hline Only Pelvic LNM & 1 & 11.1 \\
\hline Only Paraaortic LNM & 0 & 0 \\
\hline Both Pelvic and Paraaortic LNM & 0 & 0 \\
\hline \multicolumn{3}{|c|}{$\begin{array}{l}\text { Lymph node metastasis among patients } \\
\text { with grade } 3 \text { tumor and } \geq 1 / 2 \mathrm{MI}\end{array}$} \\
\hline No & 8 & 72.7 \\
\hline Yes & 3 & 27.3 \\
\hline \multicolumn{3}{|c|}{$\begin{array}{l}\text { Lymph node metastasis pattern among } \\
\text { patients with grade } 3 \text { tumor and } \geq 1 / 2 \mathrm{MI}\end{array}$} \\
\hline Only Pelvic LNM & 2 & 18.2 \\
\hline Only Paraaortic LNM & 0 & 0 \\
\hline Both Pelvic and Paraaortic LNM & 1 & 9.1 \\
\hline
\end{tabular}

Table 3. Regression analysis of grade and myometrial invasion and lymph node involvement

\begin{tabular}{|lccccc|}
\hline & B & $(\boldsymbol{\beta})$ & \%95 CI & t & p \\
\hline Grade & -0.096 & 0.335 & $0.13-0.89$ & -2.582 & 0.001 \\
Myometrial invasion & 0.051 & 0.386 & $-0.17-0.23$ & 2.613 & 0.009 \\
\hline
\end{tabular}

\section{DISCUSSION}

Staging of EC requires lymph node dissection, but the necessity and feasibility of lymphadenectomy is strongly debated. It is important to determine the risk factors that indicate that the disease may have spread to the lymph nodes in the preoperative or intraoperative period and performing lymphadenectomy in the patient group with these risk factors will be an appropriate surgical treatment option in EC. Studies have shown that lowrisk EC patients generally have a small risk of LNM (1417). Mariani et al. reported that patients with grade I, II histology, $\mathrm{MI}<50 \%$ and tumor size $<2 \mathrm{~cm}$ are at a low risk for LNM. No LNM was found in that large cohort of 381 patients with low-risk EC (13). Given these findings, the authors of the study recommend postponing lymph node dissection in patients with low-risk endometrioid type EC. Similarly, the relationship between LNM and grade and depth of MI was tried to be evaluated in early stage ECs in the current study.

Grade is an important determinant for MI and LNM. As the differentiation degree of the tumor decreases, the risk of deep MI, LNM, local recurrence and distant metastasis increases (18). As the grade increases, a higher rate of LNM can be expected. Chi et al reported the rates of LNM as $4-17 \%$ in patients with grade 2 tumors (19). Mariani et al. reported that $7 \%$ of patients with grade II tumors had LNM (13). As such, we performed a similar analysis, our study supports previously published reports showing that the risk of LNM is low in patients with low grade. In the present study, LNM was observed in only 7 (4.1\%) of 169 patients with grade I-II and $<1 / 2$ MI. It was observed that this parameter reached $11.1 \%$ for grade III and MI $<1 / 2$ tumors. Given these findings, it may be reasonable to postpone lymph node dissection in grade I-II tumors with less than $50 \%$ invasion.

The possibility of extrauterine spread and recurrence increases due to the ease of drainage into the lymphatic system in cases where the depth of invasion of the myometrium by tumoral tissues exceeds $1 / 2$ ratio (20). This is the most important pathological finding that determines whether lymphadenectomy will be added to the surgery during the operation. MI is a criterion for the tumor to behave aggressively (21). The prediction of MI, which is an indication for pelvic and paraaortic lymph node dissection in EC, allows the surgery to be planned in advance. It has been determined that the depth of $\mathrm{MI}$ is more predictive than histopathological type and grade (22). Pelvic LNM 
was reported to be $25 \%$ while paraaortic involvement was $17 \%$ in the presence of deep MI in a randomized controlled study (23). In Creasman's study, pelvic and paraaortic LNM was not observed in histologically grade I EC patients in the absence of MI (24). In our study, patients with MI limited to the endometrium or $<50 \%$ were evaluated as no deep MI. The number of patients with both no deep MI and grade I-II was 169. Pelvic LNM was detected in $1.2 \%$ of these patients, pelvic+paraaortic LNM was detected in $1.2 \%$ of patients and isolated paraaortic LNM was detected in $1.8 \%$ of the patients. There were 60 patients with grade I-II and deep MI (> 50\%) and LNM was observed in 11 (18.3\%) of 60 patients. The rate of pelvic LNM was $8.3 \%$, pelvic+paraaortic LNM rate was $10 \%$ in these patients. Our findings are consistent with Creasman's study and reveal that deep MI plays an important role in the course of EC.

The study has limitations that must be taken into account when interpreting the data. First, this study is a retrospective review of a large database. Second, the factors that may be related to LNMs, such as tumor size and lymphovascular space invasion, have not been evaluated. Another limitation of the study is that no information was provided on overall survival and disease-free survival of patients in the study cohort.

\section{CONCLUSION}

The most important finding of our study is that grade and MI are common independent markers for retroperitoneal LNM in early stage ECs and indicate the necessity of lymphadenectomy. Therefore, high grade and deep MI are important factors that should suggest lymph node dissection for clinics who consider lymph node dissection unnecessary in early stage ECs.

\section{ETHICAL DECLARATIONS}

Ethics Committee Approval: This study was approved by the Selçuk University Local Ethics Committee (Date: 15/04/2021, Decision No: 93).

Informed Consent: Because the study was designed retrospectively, no written informed consent form was obtained from patients.

Referee Evaluation Process: Externally peer-reviewed.

Conflict of Interest Statement: The authors have no conflicts of interest to declare.

Financial Disclosure: The authors declared that this study has received no financial support.

Author Contributions: All of the authors declare that they have all participated in the design, execution, and analysis of the paper, and that they have approved the final version.

\section{REFERENCES}

1. Zengin M, Eryol M, Aydemir Akkaya M, Devrim T, Yalçın S, Özkan ZS. Did the terminology of endometrial intraepithelial neoplasia resolve the chaos in the classification of endometrial hyperplasia? a 8-year retrospective study. Anatolian Curr Med J 2020; 2; 129-35.

2. Njoku K, Abiola J, Russell J, Crosbie EJ. Endometrial cancer prevention in high-risk women. Best practice \& research Clinical Obstetrics \& Gynaecology 2020; 65: 66-78.

3. Braun MM, Overbeek-Wager E, Grumbo RJ. Diagnosis and management of endometrial cancer. Am Fam Physician 2016; 93: 468-74.

4. Chan JK, Cheung MK, Huh WK, et al. Therapeutic role of lymph node resection in endometrioid corpus cancer: a study of 12,333 patients. Cancer 2006; 107: 1823-30.

5. May K, Bryant A, Dickinson HO, Kehoe S, Morrison J. Lymphadenectomy for the management of endometrial cancer. Cochrane Database Syst Rev 2010; 1: CD007585.

6. Al Hilli MM, Podratz KC, Dowdy SC, et al. Preoperative biopsy and intraoperative tumor diameter predict lymph node dissemination in endometrial cancer. Gynecol Oncol 2013; 128: 294-9.

7. Kang S, Todo Y, Odagiri T, et al. A low-risk group for lymph node metastasis is accurately identified by Korean gynecologic oncology group criteria in two Japanese cohorts with endometrial cancer. Gynecol Oncol 2013; 129: 33-7.

8. Creasman WT. The current status of lymphadenectomy in the management of endometrial cancer. Women's Health (London, England) 2011; 7:33-5.

9. Panici PB, Basile S, Maneschi F, et al. Systematic pelvic lymphadenectomy vs no lymphadenectomy in early-stage endometrial carcinoma: randomized clinical trial. JNCI: J National Cancer Institute 2008; 100: 1707-16.

10. Amant F, Neven P, Vergote I. Lymphadenectomy in endometrial cancer. The Lancet 2009; 373: 1169-70.

11. Carlson JW, Kauderer J, Hutson A, et al. GOG 244-The lymphedema and gynecologic cancer (LEG) study: Incidence and risk factors in newly diagnosed patients. Gynecol Oncol 2020; 156: 467-74.

12. Soliman PT, Frumovitz M, Spannuth W, et al. Lymphadenectomy during endometrial cancer staging: practice patterns among gynecologic oncologists. Gynecol Oncol 2010; 119: 291-4.

13. Mariani A, Webb MJ, Keeney GL, Haddock MG, Calori G, Podratz KC. Low-risk corpus cancer: is lymphadenectomy or radiotherapy necessary? Am J Obstet Gynecol 2000; 182: 1506-19.

14. Convery PA, Cantrell LA, Di Santo N, et al. Retrospective review of an intraoperative algorithm to predict lymph node metastasis in low-grade endometrial adenocarcinoma. Gynecol Oncol 2011; 123: 65-70.

15. Creasman WT, Morrow CP, Bundy BN, Homesley HD, Graham JE, Heller PB. Surgical pathologic spread patterns of endometrial cancer: a Gynecologic Oncology Group study. Cancer 1987; 60: 2035-41.

16. Milam MR, Java J, Walker JL, et al. Nodal metastasis risk in endometrioid endometrial cancer. Obstet Gynecol 2012; 119: 286.

17. Shah C, Johnson EB, Everett E, et al. Does size matter? Tumor size and morphology as predictors of nodal status and recurrence in endometrial cancer. Gynecol Oncol 2005; 99: 564-70.

18. Kadar N, Malfetano JH, Homesley HD. Determinants of survival of surgically staged patients with endometrial carcinoma histologically confined to the uterus: implications for therapy. Obstet Gynecol 1992; 80: 655-9.

19. Chi D, Barakat R, Palayekar M, et al. The incidence of pelvic lymph node metastasis by FiGO staging for patients with adequately surgically staged endometrial adenocarcinoma of endometrioid histology. Int J Gynecol Cancer 2008; 18: 2. 
20.Kaku T, Tsuruchi N, Tsukamoto N, Hirakawa T, Kamura T, Nakano H. Reassessment of myometrial invasion in endometrial carcinoma. Obstet Gynecol 1994; 84: 979-82.

21.Jantarasaengaram S, Praditphol N, Tansathit T, Vipupinyo C, Vairojanavong K. Three-dimensional ultrasound with volume contrast imaging for preoperative assessment of myometrial invasion and cervical involvement in women with endometrial cancer. Ultrasound in obstetrics \& gynecology : the official J Int Soc Ultrasound Obstet Gynecol 2014; 43: 569-74.

22. Soliman PT, Frumovitz M, Spannuth W, et al. Lymphadenectomy during endometrial cancer staging: practice patterns among gynecologic oncologists. Gynecol Oncol 2010; 119: 291-4.

23. Benedetti Panici P, Basile S, et al. Systematic pelvic lymphadenectomy vs. no lymphadenectomy in early-stage endometrial carcinoma: randomized clinical trial. J National Cancer Institute 2008; 100: 1707-16.

24. Creasman WT, Morrow CP, Bundy BN, Homesley HD, Graham JE, Heller PB. Surgical pathologic spread patterns of endometrial cancer. A Gynecologic Oncology Group Study. Cancer 1987; 60: 2035-41. 